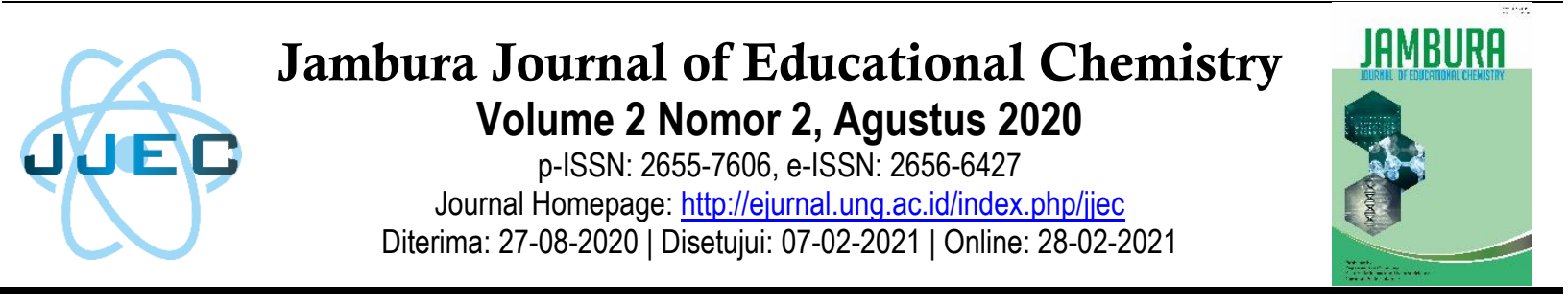

\title{
Pengaruh Model Pembelajaran Discovery Learning dengan Metode Demonstrasi Terhadap Pemahaman Konsep Reduksi Oksidasi pada Siswa Kelas X SMA Negeri 1 Suwawa
}

\author{
Asna Uge1, Astin Lukum², Opir Rumape ${ }^{3}$ \\ 1,3Prodi Pendidikan Kimia, Jurusan Kimia, Fakultas MIPA, Universitas Negeri Gorontalo \\ Jl. Prof. Dr. Ing. B. J. Habibie, Moutong, Tilongkabila, Kabupaten Bone Bolango, Gorontalo \\ 96119, Indonesia \\ e-mail: ${ }^{1}$ asnauge@gmail.com
}

\begin{abstract}
Abstrak
Penelitian ini bertujuan mengetahui pengaruh model pembelajaran Discovery Learning dengan menggunakan metode demonstrasi terhadap pemahaman Konsep reduksi oksidasi pada siswa Kelas X SMA Negeri 1 Suwawa. Penelitian ini merupakan penelitian True Experiment Design dengan Pretest-Posttest Control Group Design. Penelitian ini dilakukan di SMA Negeri 1 Suwawa dengan sampel penelitian berjumlah 54 siswa, untuk kelas eksperimen berjumlah 27 siswa dan kelas kontrol berjumlah 27 siswa. Kelas eksperimen didesign menggunakan model pembelajaran discovery learning dengan metode demonstrasi dan kelas kontrol didesign menggunakan model pembelajaran discovery learning tanpa demonstrasi. Pengumpulan data menggunakan instrumen dalam bentuk tes pemahaman konsep siswa pada materi reduksi oksidasi. Analisis data menggunakan uji-t untuk menguji hipotesis penelitian dengan taraf signifikan 5\%. Nilai thitung berdasarkan uji t adalah 4,42 yang lebih besar dari tabel 1,67 pada $\mathrm{dk}=52$. yang berarti $\mathrm{H}_{0}$ ditolak atau menerima $\mathrm{H}_{1}$. Hasil penelitian dapat disimpulkan terdapat pengaruh penggunaan model pembelajaran discovery learning dengan menggunakan metode demonstrasi terhadap pemahaman konsep siswa.
\end{abstract}

Kata Kunci: Discovery Learning; Demonstrasi; Pemahaman Konsep; Reduksi Oksidasi.

\section{PENDAHULUAN}

Mata pelajaran kimia adalah salah satu bidang mata pelajaran Ilmu Pengetahuan Alam (IPA) yang membahas tentang fenomena-fenomena yang berkaitan dengan kehidupan sehari-hari. Tujuan pembelajaran kimia yaitu agar siswa dapat menguasai dan memahami konsep-konsep serta bersikap ilmiah yang pada akhirnya dapat menyelesaikan masalah yang terdapat didalamnya.

Menurut Sudijono (2015) pemahaman konsep merupakan kemampuan individu untuk mengerti atau memahami sesuatu setelah sesuatu itu diketahui dan diingat. Pemahaman konsep juga sangat penting karena dengan memahami konsep yang benar maka siswa dapat menyerap, menguasai, dan menyimpan materi yang dipelajarinya dalam waktu yang lama. Selain itu menurut Winkel (1983), pemahaman konsep merupakan kemampuan yang dimiliki seseorang untuk mengerti atau memahami sesuatu, dengan kata lain seseorang dapat dikatakan memahami suatu hal jika seseorang itu dapat menjelaskan dan meniru hal tersebut dengan menggunakan kata-katanya sendiri serta mencakup kemampuan untuk menangkap makna dan arti dari bahan/materi yang dipelajari.

Pemahaman konsep yang jadi fokus penelitian karena dengan pemahaman, siswa dapat lebih mengerti akan konsep materi yang dipelajari 
dan dengan penguasaan konsep akan memudahkan siswa dalam mempelajari kimia. Sehingga setiap pembelajaran harusnya lebih ditekankan pada penguasaan konsep siswa terhadapt materi, agar siswa memiliki dasar yang baik dan benar untuk mencapai Kemampuan Dasar atau Standar Kompetensi. Oleh karena itu, siswa diharuskan memahami konsep kimia terlebih dahulu agar dapat menyelesaikan soal-soal sehingga mampu mengaplikasikan pembelajaran tersebut di dunia nyata.

Menurut Sugiarti (2012), hal ini sejalan dengan masalah yang dikemukakan oleh Brook \& Brooks yang mengungkapkan bahwa permasalahan penting yang dihadapi oleh dunia pendidikan sampai saat ini adalah bagaimana mengupayakan dalam membangun pemahaman. Untuk itu peserta didik diharuskan memahami dan mengerti apa saja yang diajarkan, mengetahui apa yang dikomunikasikan serta dapat memanfaatkan isinya. Dengan demikian, pembelajaran dengan pemahaman ini lebih bermakna dari pada hanya pembelajaran dengan tujuan menghafal (Saricayir et al., 2016).

Berdasarkan pengalaman PPL di SMA Negeri 1 Suwawa, sebagian besar siswa justru mengaku bahwa mereka seringkali masih mengalami kesulitan untuk memahami materi kimia, karena sebagian besar siswa hanya menghafal rumus tanpa mengetahui alur penyelesaian atau rumus awal yang dijadikan dasar dari permasalahan yang diberikan. Selain itu, banyak juga siswa yang mengaku bahwa ketika guru menjelaskan suatu pokok bahasan yang baru, terkadang mereka lupa akan inti dari pokok bahasan yang telah dijelaskan pada pertemuan-pertemuan sebelumnya. Oleh karena itu, diperlukan suatu usaha untuk dapat memperbaiki cara belajar siswa, khususnya pelajaran kimia. Salah satu konsepkonsep materi kimia SMA kelas X yang dipelajari adalah reaksi redoks atau biasa dikenal dengan reduksi dan oksidasi. Reaksi redoks merupakan salah satu materi kimia yang esensial secara umum. Isi materi yang terkandung di dalamnya merupakan aspek kimia yang sifanya abstrak yang juga membutuhkan pemahaman dan hafalan seperti penentuan bilangan oksidasi, penentuan oksidator dan reduktor, serta reaksi autoredoks.

Menurut Laliyo (2011), tantangan efektifitas dan efisiensi pengelolaan pembelajaran kimia sebenarnya terletak pada bagaimana guru menyiapkan pembelajaran yang memungkinkan siswa menguasai konsep terkait dengan pengalaman belajar yang diperolehnya selama mengikuti proses pembelajaran. Oleh karena itu materi-materi yang akan diajarkan harus bisa dijelaskan dengan baik agar siswa mengerti dan menguasai konsep dasar yang akan terus dipergunakan hingga tingkat selanjutnya, karena siswa akan mengalami kesulitan dalam mengikuti materi selanjutnya jika materi dasarnya belum berhasil mereka kuasai. Oleh katrena itu dibutuhkan model pembelajaran yang bisa mendorong siswa aktif dalam proses pembelajaran, salah satu model pembelajaran yang bisa digunakan adalah model pembelajaran discovery learning.

Model pembelajaran discovery learning adalah model pembelajaran yang mengarahkan siswa menemukan konsep melalui berbagai informasi atau data yang diperoleh melalui pengamatan atau percobaan. Discovery learning juga adalah model belajar yang menuntut guru lebih kreatif menciptakan situasi yang membuat peserta didik belajar aktif dan menemukan pengetahuan sendiri (Kartika et al., 2017). Akan tetapi, kenyataannya walaupun sudah dilakukan model pembelajaran discovery learning pemahaman siswa masih rendah, hal ini terjadi karena materi atau pelajaran tidak disampaikan dalam bentuk final dan siswa hanya didorong untuk mengidentifikasi apa yang diketahui dengan mencari informasi sendiri dan mereka pahami dalam suatu bentuk akhir. Sehingga sebagian besar siswa kesulitan dalam memahami apa yang disampaikan oleh guru. Oleh karena itu diperlukan metode yang bisa mendukung model discovery learning tersebut. Metode yang dapat mendukung model discovery learning tersebut adalah metode demonstrasi, karena dengan menggunakan metode demonstrasi ini siswa dapat mengetahui secara langsung suatu proses atau kejadian sebenarnya yang berkenaan dengan materi yang diajarkan, sehingga tidak abstrak lagi. Dengan menggunakan metode demonstrasi ini juga siswa 
menjadi lebih tertarik untuk belajar kimia dan siswa akan lebih antusias dalam pembelajaran.

Metode demonstrasi merupakan metode yang digunakan untuk melihat suatu proses atau cara kerja suatu benda yang berkenaan dengan materi pelajaran. Metode demonstrasi juga merupakan metode yang sangat efektif, karena bisa membantu siswa untuk mencari jawaban berdasarkan fakta-fakta atau data-data yang benar dengan usahanya sendiri (Djamarah \& Zain, 2000). Selanjutnya menurut Syah (2000), adapun tujuan metode demonstrasi dalam proses belajar mengajar adalah untuk memperjelas pengertian konsep dan memperlihatkan cara melakukan sesuatu atau proses terjadinya sesuatu.

Berdasarkan uraian di atas, maka permasalahan dalam peneitian ini adalah Apakah terdapat pengaruh model pembelajaran Discovery Learning dengan metode demonstrasi terhadap pemahaman konsep reduksi oksidasi pada siswa kelas X SMA Negeri 1 Suwawa? Berdasarkan rumusan masalah di atas, maka tujuan pada penelitian ini adalah untuk mengetahui pengaruh model pembelajaran discovery learning dengan metode demonstrasi terhadap pemahaman konsep reduksi-oksidasi pada siswa kelas X SMA Negeri 1 Suwawa.

\section{METODE PENELITIAN}

Penelitian ini merupakan penelitian eksperimen dengan menggunakan bentuk true experiment design dengan pretest-postest control group design.

\section{Jenis Penelitian}

Penelitian ini menggunakan pendekatan kuantitatif.

\section{Waktu dan Tempat Penelitian}

Penelitian ini dilaksanakan di SMA Negeri 1 Suwawa yang bertempat di Jalan Pasar Minggu, Kelurahan Tingkobuhu, Kecamatan Suwawa, Kabupaten Bone Bolango, Provinsi Gorontalo. Penelitian ini dilaksanakan pada semester genap tahun ajaran 2019/2020.

\section{Target/Subjek Penelitian}

Subjek dari penelitian ini adalah siswa kelas X IPA SMA Negeri 1 Suwawa tahun pelajaran 2019/2020 sebanyak 54 siswa.

\section{Prosedur}

Penelitian ini menggunakan dua kelas yaitu kelas X IPA 1(eksperimen) dan kelas X IPA 4 (kontrol) yang diambil dengan cara menggunakan cluster random sampling. Kelas ekperimen menggunakan model pembelajaran discovery learning dengan metode demonstrasi dan kelas kontrol menggunakan model pembelajaran discovery learning tanpa demonstrasi.

\section{Teknik Pengumpulan Data dan Analisis Data}

Teknik pengumpulan data pada penelitian ini dikumpulkan melalui instrument tes objektif berupa tes pemahaman konsep yang dibuat dalam bentuk two-tier multiple choice, yang berfungsi untuk mengukur kemampuan pemahaman konsep siswa. Tes ini dilakukan dua kali, yaitu sebelum perlakuan (pretest) dan sesudah perlakuan (posttest). Tehnik analisis data yang digunakan yaitu :

1. Uji normalitas data diperlukan untuk mengetahui bahwa data yang diambil berasal dari populasi yang berdistribusi normal atau tidak. Secara statistik dapat digunakan dengan metode liliefors untuk menguji hipotesis,

2. Uji homogenitas dilakukan untuk meyakinkan bahwa sampel memiliki varians yang homogenitas di berlakukan uji barllet.,

3. Uji statistik thitung digunakan untuk menguji hipotesis penelitian. Hipotesis berbunyi : terima $\mathrm{H}_{1}$ : terdapat pengaruh model pembelajaran discovery leraning dengan metode demonstrasi terhadap pemahaman konsep reduksi oksidasi pada siswa kelas X SMA Negeri 1 Suawawa bila $t_{\text {hitung }}>\mathrm{t}_{\text {tabel }}$ dan tolak $\mathrm{H}_{0}$ : tidak terdapat pengaruh model pembelajaran discovery leraning dengan metode demonstrasi terhadap pemahaman konsep reduksi oksidasi pada siswa kelas X SMA Negeri 1 Suawawa bila $t_{\text {hitung }}<$ $t_{\text {tabel. }}$

\section{HASIL DAN PEMBAHASAN}

Penelitian ini merupakan penelitian eksperimen dengan data kuantitatif yang berjudul "Pengaruh Model Pembelajaran Discovery Learning dengan Metode Demonstrasi Terhadap Pemahaman Konsep Reduksi Oksidasi pada Siswa Kelas X SMA Negeri 1 Suwawa". Penelitian ini 
dilaksanakan di SMA Negeri 1 Suwawa pada tahun pelajaran 2019/2020 dengan jumlah sampel 54 siswa yang terdiri dari kelas eksperimen yaitu 27 siswa dan kelas kontrol berjumlah 27 siswa. Adapun data yang digunakan dalam penelitian ini yaitu menggunakan instrument tes two tier multiple choice yang berjumlah 17 soal. Dimana tes two tier multiple choice adalah Instrumen tes yang terdiri dari dua tingkat, tingkat pertama terdiri atas pertanyaan pemahaman konsep dan tingkat kedua terdiri atas pilihan alasan yang mengacu pada tingkat pertama, yang merupakan data pendukung untuk memperkuat pemahaman siswa dalam memahami konsep. Data kemudian diolah secara kuantitatif dengan menggunakan uji statistik yang dilakukan sebanyak dua kali yaitu berupa pretest dan posttest. Adapun berdasarkan hasil two-tier test pemahaman konsep siswa pada pretest dan posttest kelas eksperimen dan kontrol ditunjukkan pada Tabel 1. berikut:

Tabel 1. Persentase pemahaman konsep siswa

\begin{tabular}{|c|c|c|c|}
\hline Data & Kelas & Kriteria & $\begin{array}{c}\text { Persentase } \\
(\%)\end{array}$ \\
\hline \multirow{6}{*}{ pretest } & \multirow{3}{*}{ eksp } & $\mathrm{Pk}$ & 13,1 \\
\hline & & $\mathrm{Kp}$ & 28,8 \\
\hline & & $\mathrm{Tp}$ & 58,2 \\
\hline & \multirow{3}{*}{ kontr } & $\mathrm{Pk}$ & 14,2 \\
\hline & & $\mathrm{Kp}$ & 27,5 \\
\hline & & $\mathrm{Tp}$ & 58,4 \\
\hline \multirow{6}{*}{ Posttest } & \multirow{3}{*}{ eksp } & $\mathrm{Pk}$ & 51,6 \\
\hline & & $\mathrm{Kp}$ & 21,4 \\
\hline & & $\mathrm{Tp}$ & 27,0 \\
\hline & \multirow{3}{*}{ kontr } & $\mathrm{Pk}$ & 41,6 \\
\hline & & $\mathrm{Kp}$ & 18,1 \\
\hline & & $\mathrm{Tp}$ & 40,3 \\
\hline \multicolumn{4}{|l|}{ Ket: } \\
\hline
\end{tabular}

Berdasarkan Tabel 1 dapat dilihat bahwa persentase pemahaman konsep siswa untuk kelas eksperimen lebih tinggi dibandingkan dengan kelas kontrol. Sehingga dari hasil yang diperoleh dapat dilihat bahwa metode demonstrasi lebih baik dibandingkan dengan metode tanpa demonstrasi untuk dapat meningkatkan pemahaman konsep siswa pada materi reduksi oksidasi. Dan sebagai persyaratan uji statisik hipotesis dilakukan terlebih dahulu uji normalitas dan uji homogenitas data. Hasil uji normalitas dan homogenitas data berturutturut Tabel 2 dan Tabel 3 berikut ini:

Tabel 2. Uji Normalitas menggunakan uji Liliefors

\begin{tabular}{ccccc}
\hline No & Data & $\begin{array}{c}\text { L- } \\
\text { hitung }\end{array}$ & $\begin{array}{c}\text { L- } \\
\text { tabel }\end{array}$ & Kesimpulan \\
\hline \multirow{2}{*}{1} & Ekperimen & 0,15 & 0,16 & \multirow{2}{*}{ Normal } \\
\cline { 2 - 4 } & Kontrol & 0,11 & 0,16 & \\
\hline \multirow{2}{*}{2} & Ekperimen & 0,15 & 0,16 & \multirow{2}{*}{ Normal } \\
\cline { 2 - 4 } & Kontrol & 0,15 & 0,16 & \\
\hline
\end{tabular}

Berdasarkan tabel hasil uji normalitas dengan taraf signifikan 0,05 dapat dilihat bahwa data pretest dan posttest pada kelas eksperimen dan kontrol berdistribusi normal. Hal ini dikarenakan $\mathrm{L}_{\text {hitung }} \leq \mathrm{L}_{\text {tabel, }}$, sehingga $\mathrm{H}_{0}$ diterima.

Tabel 3. Uji Homogenitas menggunakan uji Bartllett

\begin{tabular}{cccc}
\hline Kelas & $\begin{array}{c}\boldsymbol{X} \text { - } \\
\text { hitung }\end{array}$ & $\begin{array}{c}\boldsymbol{X} \text { - } \\
\text { tabel }\end{array}$ & Kesimpulan \\
\hline $\begin{array}{c}\text { Eksp dan } \\
\text { kontr }\end{array}$ & 0,29 & 11.07 & Homogen \\
\hline $\begin{array}{c}\text { Eksp dan } \\
\text { Kontr }\end{array}$ & 0,43 & 22,36 & Homogen \\
\hline
\end{tabular}

Berdasarkan tabel hasil uji homogenitas diatas diperoleh bahwa $\mathrm{X}_{\text {hitung }} \leq \mathrm{X}_{\text {tabel }}$ sehingga $\mathrm{H}_{0}$ diterima.

Setelah uji normalitas dan homogenitas terpenuhi dan data telah berdistribusi normal serta berasal dari populasi yang homogen, selanjutnya dilakukan pengujian hipotesis untuk melihat pengaruh metode demonstrasi terhadap pemahaman konsep siswa dengan menggunakan uji t. Data Uji-t dapat dilihat pada Tabel 4 berikut:

Tabel 4. Pengujian Hipotesis Menggunakan Uji-t

\begin{tabular}{lcccc} 
Kelas & Sampel & $\begin{array}{c}\text { Rata- } \\
\text { rata } \\
\text { Postest }\end{array}$ & t-hit & t-tabel \\
\cline { 1 - 3 } Eksp & 27 & 51.63 & 4,42 & 1,67 \\
\hline Kontr & 27 & 45.53 & & \\
\hline
\end{tabular}


Dari perhitungan tersebut didapatkan hasil t hitung $=4,42$ sedangkan $\mathrm{t}$ tabel $=1,67$. Dengan demikian diketahui bahwa $\mathrm{t}$ hitung $\geq \mathrm{t}$ tabel yaitu 4,42 $\geq 1,67$ yang berarti $\mathrm{H}_{1}$ diterima dan $\mathrm{H}_{0}$ ditolak. Hal ini menunjukan bahwa terdapat pengaruh model pembelajaran discovery learning dengan metode demonstrasi terhadap pemahaman konsep reduksi oksidasi pada siswa kelas X SMA Negeri 1 Suwawa.

\section{KESIMPULAN}

Berdasarkan data-data penelitian dan hasil perhitungan diperoleh bahwa: Model pembelajaran discovery learning dengan metode demonstrasi berpengaruh terhadap pemahaman konsep siswa. Dimana untuk uji $\mathrm{t}$ hasil yang diperoleh $\mathrm{t}_{\text {hitung }} \geq \mathrm{t}$ tabel $(4,42>1,67)$. Hasil tersebut menunjukkan bahwa terdapat pengaruh model pembelajaran discovery learning dengan metode demonstrasi terhadap pemahaman konsep reduksi oksidasi pada siswa SMA Negeri 1 Suwawa.

\section{UCAPAN TERIMA KASIH}

Terima kasih penulis sampaikan kepada Ibu Prof. Dr. Astin Lukum, M.Si selaku Penasehat Akademik sekaligus Pembimbing I dan Bapak Dr.Opir Rumape M.Si selaku Pembimbing II. yang telah meluangkan waktu dengan tulus dan ikhlas membimbing dan membantu serta memberi motivasi, saran, semangat, arahan dan dorongan sehingga saya dapat menyelesaikan skripsi ini. Doaku semoga Allah SWT membalas dengan kebaikan yang lebih. Aamiin.

\section{DAFTAR PUSTAKA}

Djamarah, S. B., \& Zain, A. (2000). Eds Revisi: Strategi Belajar Mengajar. PT. Rineka Cipta.

Kartika, E. R., Rudibyani, R. B., \& Efkar, T. (2017). Penerapan Discovery Learning Dalam Meningkatkan Kemampuan Berpikir Orisinil Materi Elektrolit/Non Elektrolit. Jurnal Pendidikan Dan Pembelajaran Kimia, 6(1), 62-73.

Laliyo, L. A. R. (2011). Model mental siswa dalam memahami perubahan wujud zat. Jurnal Penelitian Dan Pendidikan, 8(1), 1-12.

Saricayir, H., Ay, S., Comek, A., Cansiz, G., \& Uce, M. (2016). Determining Students' Conceptual Understanding Level of Thermodynamics. Journal of Education and Training Studies, 4(6), 69-79.

Sudijono, A. (2015). Pengantar evaluasi pendidikan.

Sugiarti, A. A. S. (2012). Pengaruh Penerapan Model Pembelajaran Kooperatif GI terhadap Pemahaman Konsep Kimia dan Kemampuan Berpikir Kreatif Siswa SMAN 3 Denpasar. Jurnal Pendidikan Dan Pembelajaran IPA Indonesia, 2(1).

Syah, M. (2000). Psikologi Belajar Mengajar. Bumi Aksara.

Winkel, W. S. (1983). Psikologi Pendidikan dan Evaluasi Belajar. PT Gramedia, Jakarta. 